\title{
BENEFÍCIOS COMPETITIVOS E CONFLITOS EM REDE HORIZONTAL DO SETOR SUPERMERCADISTA
}

\author{
Ari de Souza Soares \\ arisoares@gmail.com \\ Universidade Federal de Lavras - MG/Brasil \\ Cleber Carvalho de Castro \\ clebercastro@dae.ufla.br \\ Universidade Federal de Lavras - MG/Brasil \\ Mozar José de Brito \\ mozarjdb@ufla.br \\ Universidade Federal de Lavras - MG/Brasil \\ Rosália Rodrigues Alves \\ rosaliaadm@gmail.com \\ Universidade Federal de Lavras - MG/Brasil
}

Recebido 25/02/2009

Aprovado em 08/09/2010

Disponibilizado em 01/08/2011

Avaliado pelo sistema double blind review

Revista Eletrônica de Administração

Editor: Luís Felipe Nascimento

ISSN 1413-2311 (versão on-line)

Editada pela Escola de Administração da Universidade Federal do Rio Grande do Sul.

Periodicidade: Quadrimestral

Sistema requerido: Adobe Acrobat Reader.

\section{INTRODUÇÃO}

A palavra "rede", cada vez mais, tem se tornado comum para descrever uma série de fenômenos que vão desde práticas sociais até atividades econômicas. Nohria (1992) destaca que, no contexto dos estudos organizacionais, o termo tem sido usado tanto para se referir ao padrão das organizações quanto, normativamente, tem sido apresentado como um caminho a ser seguido na busca por vantagens econômicas. Com efeito, entende-se que, embora ramificadas em variadas estruturas, as redes apresentam como elo comum, o agrupamento 
Ari de Souza Soares, Cleber Carvalho de Castro, Mozar José de Brito \& Rosália Rodrigues Alves

como estratégia competitiva.

Ao mesmo tempo, a diversidade de formação destes arranjos empresarias no contexto do setor supermercadista tem suscitado um importante debate sobre a eficiência do ponto de vista competitivo e dos desafios de coordenação.

Nasce daí o interesse, do presente estudo, de investigar a competitividade das redes de acordo com a lógica das relações interorganizacionais estabelecidas e os benefícios e os conflitos advindos dessas parcerias. Neste sentido, este trabalho busca elucidar a seguinte questão de pesquisa: quais são os benefícios competitivos e os conflitos de interesses percebidos na participação de empresas do setor supermercadista em uma rede horizontal na região sul de Minas Gerais?

De um lado, a discussão sobre competitividade abrange práticas estratégicas de ganhos mútuos, proporcionadas, em síntese, por um volume maior de transações e pelo fortalecimento do know-how compartilhado. Assim, quando falarmos em benefícios competitivos, o termo abrangerá tanto resultados econômicos diretos (maior receita e menor despesa operacional) quanto ganhos indiretos (Valorização da imagem do negócio, capital social, aprendizado, etc.).

Por outro lado, a interdependência estabelecida, pelo compartilhamento de recursos comuns e decisões coletivas, sugere a existência de conflitos pautados pela dificuldade de conciliar os objetivos de cada negócio com os propósitos gerais da rede. Deste modo, para melhor precisão conceitual, tais conflitos de interesses percebidos se referem à visão que um dado participante possui e que destoa do discurso coletivo de rede. Isto ocorre, por exemplo, quando um participante percebe que outro não está compartilhando informação ou que está tomando decisões com o objetivo exclusivamente individual de ganhos.

Justifica-se esse interesse de pesquisa em virtude do fato de que, do ponto de vista teórico, a importância do fenômeno dos relacionamentos cooperativos em rede tem despertado o interesse de pesquisadores das mais variadas áreas do conhecimento, como antropologia, psicologia, sociologia, biologia molecular, etc. (NOHRIA, 1992). Decorre também dessa marcante interdisciplinaridade, a aglutinação destes pesquisadores em torno de diversos temas, como cultura em redes (KRUG, 2003; KOEN; BEUGELSDIJK; NOORDERHAVEN, 2006), relações de poder nas redes (COOK, 1983; MARSDEN, 1983), processos políticos das redes (ELG; JOHANSSON, 1997), entre outros. Isto tem feito com 
Benefícios competitivos e conflitos em rede horizontal do setor supermercadista que o tema esteja cada vez mais em evidência, seja como resposta às pesquisas que vêm sendo desenvolvidas (GULATI; NOHRIA; ZAHEER, 2000), seja para dar conta das mudanças que têm ocorrido em vários setores da economia.

No âmbito empírico, por sua vez, a importância das redes do setor supermercadista na economia brasileira é atestada pelos dados apresentados na $8^{\text {a }}$ Pesquisa sobre Redes de Negócios Abras/SuperHiper. Realizada em parceria com a Latin Panel, esta pesquisa revela que o setor de redes possui um total de 2,84 mil lojas no Brasil, abrangendo 11,7 mil checkouts e área total de vendas de 1,4 milhão de metros quadrados, respondendo por 69,6 mil empregos. Ao mesmo tempo, embora o associativismo represente ainda apenas $10 \%$ do universo varejista, as perspectivas de crescimento são bastante favoráveis, sobretudo, tomando-se por base a pretensão dos participantes em realizar investimentos, como criação de novas lojas (67\%), aquisição de equipamentos (57\%) e compra de terrenos (24\%), entre outros (CARLESSI, 2008).

Este trabalho está estruturado da seguinte forma: a seguir (seção 2) são apresentados conceitos e aspectos ligados à tipologia das redes horizontais. Na seção 3, destacam-se vantagens e conflitos envolvidos na discussão sobre redes interorganizacionais. $\mathrm{Na}$ seção 4 , contextualizam-se as redes no âmbito do setor supermercadista e na seção 5 são apresentados os métodos e procedimentos utilizados na realização deste trabalho. Em seguida, na seção 6 são apresentados os resultados da pesquisa, explicitando os benefícios competitivos e conflitos observados na rede horizontal estudada. Por fim, na seção 7 são tecidas as considerações finais deste estudo.

\section{As redes horizontais}

O estudo das redes a partir de uma perspectiva horizontal decorre do reconhecimento de que a disposição estrutural dos membros participantes está associada a um conjunto de características próprias destes arranjos.

O primeiro aspecto distintivo das redes horizontais advém da ausência de uma hierarquia imposta sobre seus participantes. Entende-se que tais arranjos surgem e operam a partir de decisões tomadas de forma conjunta - one head one vote - embora se perceba que certos atores assumam posições de maior centralidade. Tais características podem assumir diferentes graus, segundo a variedade das atividades produtivas ou dos fatores locais que 
Ari de Souza Soares, Cleber Carvalho de Castro, Mozar José de Brito \& Rosália Rodrigues Alves

singularizam cada fenômeno.

No trabalho de Olivares (2003), o autor procura organizar a diversidade de redes horizontais ao propor uma síntese das perspectivas teóricas delineadas por diferentes autores, tratando do tema e da ideia básica de cada abordagem, conforme Quadro 1. A interpretação do autor para os arranjos horizontais, conforme sugerido por este, guiou-se pela ideia de ligações de empresas concorrentes à procura de relacionamentos de cooperação.

\begin{tabular}{|c|c|c|}
\hline AUTOR & NOME DO TIPO DE REDE & IDEIA BÁSICA \\
\hline Casarotto Filho e Pires & Rede flexível. & $\begin{array}{l}\text { Consórcio de organizações } \\
\text { (alianças). }\end{array}$ \\
\hline Ernst & $\begin{array}{l}\text { Rede de produtores. } \\
\text { Rede de coalizões padrões. } \\
\text { Redes de cooperação. }\end{array}$ & $\begin{array}{l}\text { Coprodução. } \\
\text { Interface. } \\
\text { Desenvolvimento conjunto. }\end{array}$ \\
\hline \multirow[t]{2}{*}{ Van de Ven } & $\begin{array}{l}\text { Relação interorganizacional } \\
\text { (modo par). }\end{array}$ & $\begin{array}{l}\text { Uma organização } \\
\text { individualizada com outra } \\
\text { organização. }\end{array}$ \\
\hline & $\begin{array}{l}\text { Relação conjunto } \\
\text { interorganizacional. }\end{array}$ & $\begin{array}{l}\text { Uma organização } \\
\text { individualizada com cada uma } \\
\text { das outras organizações. }\end{array}$ \\
\hline Veereck e Van Dierdonck & Rede federação descentralizada. & $\begin{array}{l}\text { Relação com parceiros locais em } \\
\text { cada país. }\end{array}$ \\
\hline Perrow & $\begin{array}{l}\text { Redes de pequenas empresas } \\
\text { (clusters cooperativos). }\end{array}$ & Relações de Co-opetition. \\
\hline Castells & $\begin{array}{l}\text { Redes horizontais japonesas } \\
\text { (kigyo shudan). }\end{array}$ & $\begin{array}{l}\text { Conexões de grandes } \\
\text { organizações intermercados. }\end{array}$ \\
\hline
\end{tabular}

Quadro 1: Suporte teórico para definir rede horizontal Fonte: Olivares (2003)

Baum e Ingram (2000) chamam a atenção para o fato de que as redes horizontais são formadas por organizações similares e, por isso mesmo, com grande potencial para serem competidoras entre si. No entanto, os autores argumentam que as redes são estruturadas a partir de um conjunto de fatores interdependentes - econômicos e não-econômicos - que facilitam a cooperação organizacional em função de interesses diversos.

Para Casarotto Filho e Pires (1998), os relacionamentos horizontais são chamados de "redes flexíveis", dado que se originam de um consórcio com vistas a realizar operações específicas ou, de forma mais ampla, enfrentar a concorrência por meio de maior flexibilidade na diferenciação de produtos.

Ernst (1994), por seu turno, qualifica as redes horizontais de três formas: a) rede de 
Benefícios competitivos e conflitos em rede horizontal do setor supermercadista produtores: relaciona acordos de coprodução no intento de conciliar recursos complementares, para a ampliação de portfólio; b) rede de coalizões padrões: formada por empresas com habilidades para definir padrões globais, com a finalidade de agrupar padrões de interface e c) redes de cooperação: visam à aquisição de tecnologias e ao compartilhamento de conhecimentos para o desenvolvimento conjunto de produtos e processos.

Castells (2007) chama a atenção para as redes horizontais japonesas, postas em prática por empresas de pequeno e médio porte. Estas redes, denominadas Kigyo Shudan, são construídas a partir de relações sinérgicas formadas tipicamente para projetos conjuntos. Hoje, conforme Scher (1999), as Kigyo shudan incluem grupos de firmas horizontalmente ligadas e, geralmente, centralizadas por um grupo financeiro ou industrial.

Perrow (1992), por sua vez, relaciona os arranjos horizontais com a presença de pequenas empresas, que interagem e compartilham equipamentos, pessoas, etc., num misto de cooperação e competição - co-opetition. O autor enfatiza a importância da confiança como “ativo" capaz de uma maximização do comportamento individual em um grupo de firmas.

Conforme Bengtsson e Kock (1999), uma empresa pode se envolver ao mesmo tempo em quatro diferentes tipos de relacionamento horizontal, de forma que tanto pode estabelecer uma relação simbiótica pela coexistência quanto pode se envolver em um relacionamento que, simultaneamente, contenha elementos de cooperação e competição. Conforme os autores, tais relacionamentos são mais informais e invisíveis, dado que são construídos, principalmente, por meio da informação e das trocas sociais.

Baseando-se no trabalho de Easton \& Araujo (1992), Bengtsson \& Kock (1999) propõem quatro tipos de alianças estratégicas horizontais, quais sejam: coexistência, cooperação, competição e co-opetição. Abaixo se verifica uma síntese de cada um desses tipos de relacionamentos (BENGTSSON \& KOCK, 1999, p.181):

a) coexistência: o relacionamento não inclui trocas econômicas, apenas trocas sociais e de informação. Nesta situação, embora os membros conheçam um ao outro, eles não interagem com todos. A distância entre os membros é baseada em fatores psicológicos e os objetivos são estipulados de forma independente;

b) cooperação: as trocas são frequentes e compreendem trocas sociais, de informação e negócios. Todos os tipos de limites podem surgir, embora os mais comuns estejam relacionados com os aspectos sociais, de conhecimento e legal/econômicos. Embora 
Ari de Souza Soares, Cleber Carvalho de Castro, Mozar José de Brito \& Rosália Rodrigues Alves

os membros cooperem, isso não impede que haja competição ou desconfiança entre eles. Os relacionamentos podem ter um conteúdo formal (por exemplo, acordos formando alianças estratégicas) ou informal (pela construção de normas sociais e de confiança). Os conflitos são raros, os membros têm objetivos comuns e a proximidade entre eles é baseada em fatores funcionais e psicológicos;

c) competição: este relacionamento emerge como um padrão de ação-reação, no qual, por exemplo, se um membro lança uma nova linha de produtos, os outros imediatamente os seguirão. A proximidade ou a distância entre os membros é baseada em fatores psicológicos e funcionais, e o poder e a dependência baseiam-se na posição deles na rede de negócios;

d) coopetição: este relacionamento pode incluir trocas econômicas e não-econômicas. A dependência pode ocorrer por dois caminhos. Quando cooperam, a dependência é estipulada em acordos formais ou é baseada na confiança. Quando competem, a dependência se dá pela força de um ator e sua posição na rede de negócios. Os conflitos são raros, embora a competição seja frequente. Existem normas claras para a cooperação baseada em acordos formais; porém, quando competem, as normas são invisíveis e fazem parte do clima de competição. Assim, os objetivos são estipulados de forma conjunta quando cooperam, o que não ocorre quando competem.

Neste sentido, Balestrin e Vargas (2004) apresentam as redes horizontais como um recurso estratégico para melhorar o desempenho competitivo das PMEs. Conforme os autores, as redes horizontais "são constituídas por empresas que guardam cada uma sua independência, mas que optam por coordenar certas atividades específicas de forma conjunta" (BALESTRIN; VARGAS, 2004, p.208). Os objetivos, geralmente, giram em torno da criação de novos mercados, desenvolvimento de novos produtos, ações de marketing conjuntos, etc.

\section{Benefícios competitivos e conflitos nas redes}

As alianças geram vantagem competitiva apenas quando elas constroem relacionamentos diferentes dos atributos das relações de mercado. Ou seja, a ideia subjacente é que as vantagens e as desvantagens de uma firma individual estão frequentemente ligadas às 
Benefícios competitivos e conflitos em rede horizontal do setor supermercadista vantagens e desvantagens dos relacionamentos em rede nas quais a firma está imersa.

Enquanto na firma isolada a diferenciação entre as unidades é fonte de custos de coordenação, ocasionando falhas burocráticas, nas redes elas são capazes de lidar melhor com a diferenciação, já que neste formato ela funciona como fator de complementaridade e diversidade (GRANDORI; SODA, 1995). As firmas, dessa forma, podem expandir suas atividades além de seus limites, reforçando as ideias de Economides (1996), segundo o qual, o surgimento de externalidades decorre justamente da complementaridade entre os componentes de uma rede.

A importância da complementaridade é enfatizada também por Brandenburger e Nalebuff (1996) como diferencial para o sucesso ou fracasso dos negócios. Sob esta ótica, grupos de "players" fornecem os complementos capazes de tornar um produto ou serviço mais atrativo. Tais complementos devem ser sempre recíprocos e a utilização conjunta produz uma sinergia capaz de elevar seu valor individual.

Outro fator positivo advindo da complementaridade entre os participantes destes arranjos é a maior flexibilidade das redes. Esta flexibilidade não significa apenas capacidade de mudança dos resultados da firma diante da contingência do ambiente, mas também capacidade do arranjo organizacional por si mesmo (GRANDORI; SODA, 1995). Representa, como bem identificou Castells (2007, p.215), uma "maior diferenciação dos componentes de trabalho e capital da unidade de produção", gerando maiores incentivos e responsabilidades.

Outro fator que, pelas relações estabelecidas, propõe maior competitividade para as redes é a questão do aprendizado. Podolny e Page (1998) observaram que estes arranjos impulsionam também o aprendizado, pois preservam uma grande diversidade de rotinas. Os autores destacam que há duas formas das redes impulsionarem o aprendizado: primeiro, pela promoção de transferência rápida de informação e, segundo, pelo encorajamento de síntese de informação qualitativamente superior e distinta daquela que reside dentro dos nós da rede.

Dyer e Singh (1998) também chamam a atenção para a "rotina compartilhada de conhecimento". Estes autores partem da ideia de que as organizações frequentemente aprendem pela colaboração com outras organizações. Esta rotina permite às firmas transferir, recombinar ou criar conhecimento especializado, obtendo novas fontes de know-how localizado fora dos limites da firma, conduzindo-as a um melhor desempenho nos processos de inovação. Isso ocorre por meio do acesso mais rápido a novas tecnologias e do empreendimento de pesquisa conjunta. 
Ari de Souza Soares, Cleber Carvalho de Castro, Mozar José de Brito \& Rosália Rodrigues Alves

Em consonância com tais ideias, observa-se que o conhecimento nas redes de cooperação interempresarial é gerado de forma mais eficiente e rápida. Isto faz com que o fluxo de pessoas, informações e materiais entre as organizações participantes propulsione a atualização de seu estoque de conhecimento e a criação de novos produtos (NAKANO, 2005). Embora este processo de transmissão do conhecimento não seja fácil e automático, as redes fornecem uma estrutura favorável à socialização entre os indivíduos - por meio do contato pessoal - incentivando, por exemplo, a transmissão de conhecimento tácito.

Outro benefício, também considerado como importante fator facilitador do fluxo de informações dentro de uma rede está na existência de confiança entre os agentes, configurando-a como um forte capital social coletivo (NAKANO, 2005). Neste sentido, Perrow (1992) apresenta algumas como consequência das redes de pequenas firmas, a produção de confiança, que figura como um "ativo" capaz de fornecer vantagens competitivas. A atmosfera de confiança torna ainda possível conduzir, de forma mais eficiente, a resolução de problemas, uma vez que faz com que a informação seja trocada de forma mais livre, além de permitir que uma maior quantidade de soluções seja dada para um mesmo problema. Porém, a confiança também pode criar brechas nos relacionamentos interorganizacionais capaz de conduzir a comportamentos oportunistas e conflituosos.

Ocorre que as relações per se não são condição suficiente para ensejar um comportamento honesto e de confiança, uma vez que fornece os meios (ocasião e recursos) capazes de fomentar igualmente a má-fé e o conflito numa escala, inclusive, mais ampla (GRANOVETTER, 1985). Ou seja, a constituição de uma confiança cria oportunidade para ações oportunistas, em virtude da vulnerabilidade das partes expostas no relacionamento.

A partir disso, percebe-se que reconhecer os benefícios competitivos nos relacionamentos interorganizacionais significa buscar um caminho no qual as organizações, estando imersas e mais estreitamente relacionadas, insinuam também um ambiente mais propício ao conflito.

O conflito no ambiente das redes é facilitado em função da proximidade entre os agentes e das diferentes posições adotadas por estes no processo de tomada de decisão. $\mathrm{O}$ conflito nas redes exige, nesse sentido, uma abordagem dinâmica das ações e comportamentos a partir de um quadro amplo que leve em conta fatores não apenas econômicos, mas também socioculturais, psicológicos e de outra natureza. 
Benefícios competitivos e conflitos em rede horizontal do setor supermercadista

Ouchi (1980), baseando-se em Mayo e Barnard, destaca que um problema fundamental da cooperação advém do fato de os indivíduos terem objetivos apenas parcialmente sobrepostos. Isso cria uma situação na qual aqueles objetivos individuais que não se sobrepõem harmonicamente o fazem potencialmente de forma conflituosa. A importância dos estudos sobre conflitos em rede surge justamente em virtude do imbricamento das ações, da tênue linha que divide a cooperação da competição e dos recursos, interesses e culturas que, não obstante serem diversos, na rede, devem tomar uma direção comum (ASSAEL, 1969).

Uma das premissas para abordar a questão dos conflitos é observar que os relacionamentos não são estáticos, mas dinâmicos e contêm sempre situações de harmonia e conflito. Rhenman, Strömberg e Westerlund (1970) definem o conflito como uma quebra ou ameaça para a cooperação. Boulding (1963) entende o conflito como uma incompatibilidade percebida pelas partes envolvidas, enquanto Alter (1990) relaciona o conflito como uma quantidade de desarmonia e discussão entre as organizações de um sistema.

Para Gaski (1984), o conflito representa uma tensão entre duas ou mais entidades sociais que surge da incompatibilidade de respostas atuais ou desejadas. Dessa distinção de respostas, costuma-se separar o conflito em duas dimensões: conflito manifesto (ações públicas) e conflito subjacente (interesses e desejos). Para Laine (2002), o primeiro caso conflito público - ocorre quando todos os atores têm consciência da existência do conflito, enquanto no segundo, quando é subjacente - coberto -, a situação de conflito é percebida por apenas um dos atores dentro do relacionamento.

Conforme Rahim (2000), o conflito tem um lado bom e um lado ruim, de forma que alguns conflitos devem ser eliminados enquanto outros devem permanecer. Para Assael (1969), o conflito entre organizações é inevitável em função da interdependência e dos recursos escassos, embora eles possam ter consequências construtivas.

Os conflitos construtivos são potencialmente benéficos para o sistema quando eles proporcionam maior equidade alocativa das políticas de poder e dos recursos econômicos, na formação de nova força e na estabilidade do sistema. O conflito é destrutivo quando há falta de reconhecimento dos objetivos mútuos de resultado (ASSAEL, 1969).

De forma positiva, um nível médio de conflito pode ser útil na medida em que conduz os grupos a tarefas não rotineiras (JEHN, 1995), da mesma forma que pode criar uma comunicação melhor, com uma visão mais crítica (ASSAEL, 1969). Nesta mesma linha, 
Ari de Souza Soares, Cleber Carvalho de Castro, Mozar José de Brito \& Rosália Rodrigues Alves

outros autores (BROWN, 1983; PASCALE, 1990; PONDY, 1967) argumentam também que os conflitos podem estimular a criatividade e o desenvolvimento.

\section{Redes no setor supermercadista}

As redes de supermercados - centrais de compras ou associativismo - vêm ganhando importância não apenas no Brasil, mas em diversos outros países, como Itália, Japão, Alemanha, México, Argentina, Chile, etc. (CARVALHO; GHISI; MARTINELLI, 2004). A ideia do associativismo supermercadista tem se difundido com tanta evidência que diferentes formatos e arranjos têm surgido. Carvalho (2005) distingue dois tipos de centrais: a) independentes: formadas por pequenas lojas que se juntam para realizar compras e, eventualmente, dividir custos como máquinas e equipamentos e b) patrocinadas: centrais originadas por atacadistas que reúnem em torno de si lojas independentes. No primeiro caso, temos as denominadas redes horizontais e, no segundo, as redes verticais.

As redes são apontadas como uma das principais alternativas para o aumento de competitividade das PMEs do setor. O objetivo de constituição dessas redes tem sido quase sempre aumentar o poder de negociação junto às indústrias, com vistas à obtenção de preços e condições melhores de pagamentos.

No entanto, embora se fale muito dos benefícios decorrentes deste associativismo, é preciso atentar para alguns problemas presentes neste tipo de rede. Carvalho (2005, p.36) chama a atenção para o fato de que a "organização precária, pouco profissionalismo e desconfiança entre os associados são desafios que as centrais precisam enfrentar e resolver". Da mesma forma que, embora a principal motivação para a formação de centrais de compra tenha sido a busca por preços melhores, verifica-se que as negociações feitas nestas centrais comportam um número reduzido de produtos, geralmente aqueles que são encartados nos jornais promocionais, o que, muitas vezes, gera frustração por parte dos associados.

Zentes e Bernhard (2000) destacam que as redes de compras realizam um percurso evolutivo. Primeiramente, tais redes são caracterizadas pela condição de compra conjunta favorável, produzindo efeitos positivos tanto no mercado quanto na relação com os fornecedores. Num segundo momento, ocorre uma reorientação estratégica no nível de 
Benefícios competitivos e conflitos em rede horizontal do setor supermercadista tomada de decisão e comprometimento entre os associados. Por fim, num estágio de maior maturidade, estas redes deixam de ter como foco os processos de compra e passam a ser concentrar em ações conjuntas direcionadas ao consumidor.

À medida que se intensifica o processo de formação das redes de supermercados, tem se tornado patente uma mudança de visão, pelo menos de caráter prescritivo, de que, em vez de se preocupar em realizar melhores compras, o supermercadista deve ter como foco realizar melhores vendas. Tal questão pode ser sintetizada na ideia de que "o desafio das centrais brasileiras é passar da fase de comprar em conjunto para a fase de vender em conjunto" (CARVALHO, 2005, p.40). Com isso, percebe-se uma evolução do conceito de "centrais de compras" para "centrais de negócios".

\section{Método e procedimentos}

O presente estudo foi desenvolvido com base na perspectiva da pesquisa qualitativa. A pesquisa qualitativa abrange vários métodos, envolvendo aspectos interpretativos, naturais e de questões subjetivas. Isso significa que a pesquisa qualitativa estuda coisas no seu conjunto natural, tentando interpretar os fenômenos em termos do que eles significam para as pessoas que os constroem (DENZIN; LINCOLN, 1994)

Dentre os tipos de pesquisa qualitativa, o estudo de casos é um dos mais relevantes (TRIVIÑOS, 1987) e foi o escolhido para o desenvolvimento da parte empírica deste trabalho. De acordo com Yin (2001, p.19), o estudo de caso é uma investigação empírica de um fenômeno contemporâneo no contexto da vida real. Trata-se de um método adequado para responder a questões explicativas do tipo "como" e "por que", de caráter mais explanatório e que são construídas a partir de ligações operacionais traçadas ao longo do tempo. Caracterizam-se, pois, por sua dinâmica em lidar com uma variedade de evidências: documentos, artefatos, entrevistas e observações.

Assim, com base nas pressuposições metodológicas da pesquisa qualitativa, e nas contribuições de Yin (2005) e Triviños (1987), buscou-se desenvolver uma pesquisa multicasos, no intuito de analisar os benefícios competitivos e os conflitos percebidos da participação do comércio varejista em redes horizontais na região sul de Minas Gerais.

Os dados foram coletados de fontes secundárias e primárias. Os principais dados secundários foram obtidos da Associação Brasileira de Supermercados (ABRAS), da 
Ari de Souza Soares, Cleber Carvalho de Castro, Mozar José de Brito \& Rosália Rodrigues Alves

Associação Mineira de Supermercados (AMIS) e das redes e empresas envolvidas na pesquisa. As fontes dos dados primários foram obtidas por meio de oito entrevistas realizadas a partir de um roteiro semiestruturado com as empresas participantes da rede Unissul - União dos Supermercadistas Sulmineiros - caracterizada como uma rede horizontal, coordenada pelos próprios participantes.

Para a realização das entrevistas, inicialmente, fez-se um contato por telefone com os possíveis entrevistados das redes. Utilizou-se o critério de conveniência (proximidade com a cidade de Lavras) na seleção desses entrevistados. Após uma explicação dos objetivos do trabalho, estes foram convidados a participar da pesquisa por meio da concessão de uma entrevista. As entrevistas ocorreram, geralmente, no próprio supermercado do participante da rede.

O roteiro de entrevistas foi elaborado no intuito de obter informações acerca dos aspectos competitivos e dos conflitos existentes nos relacionamentos em rede. Nesse sentido, subsequentemente foram introduzidas questões como a motivação/objetivo de fazer parte da rede, o funcionamento e a rotina, os serviços prestados, as dificuldades e, por fim, os conflitos.

Todas as entrevistas foram gravadas e posteriormente transcritas. Seguindo o critério qualitativo de saturação (BARDIN, 2007), as entrevistas foram suspensas a partir do momento em que não se observou o surgimento de novos elementos relevantes, isto é, quando as respostas começaram a se apresentar repetitivas. Realizada esta etapa, passou-se para a transcrição e a análise dos resultados.

Após a transcrição das entrevistas gravadas, foi realizada a análise de conteúdo destas com o apoio do software Sphinx léxica 5.0, que possui diversos recursos de análise qualitativa de dados. O software Sphinx tem sido bastante utilizado no campo de estudos organizacionais, conforme se observa de forma exemplificativa nos estudos de Pozzebon, Freitas e Petrini (1997), Stroeher e Freitas (2008), Grisci e Dengo (2003), Nascimento e Pessoa (2007), Vieira (2002) e Machado e Antunes (2007).

A análise de conteúdo é um conjunto de técnicas de análise das comunicações a partir das quais, de forma sistemática e objetiva, é possível descrever o conteúdo das mensagens (BARDIN, 2007). Pode-se, com isso, obter indicadores quantitativos ou não, úteis no processo de dedução das condições de produção da mensagem, na classificação dos conceitos, 
Benefícios competitivos e conflitos em rede horizontal do setor supermercadista codificação e categorização.

A utilização do software Sphinx léxica 5.0 objetivou organizar a exploração de dados para a análise de conteúdo. O software analisa entrevistas, discursos e dados textuais, integrando, numa mesma plataforma, aspectos quantitativos e qualitativos, por meio de análises temáticas, léxicas, de vocabulário e contextos (FREITAS et al, 2002). Ele facilita a análise de conteúdo na medida em que permite investigar textos em profundidade, oferecendo funções de divisão, hipertexto, indexação e identificação de segmentos repetitivos (FREITAS et al., 2002).

\section{Benefícios competitivos e conflitos em uma rede horizontal}

\subsection{A rede Unissul}

A Rede Unissul teve início em abril de 2001, quando, por iniciativa de um grupo de proprietários de supermercados localizados na região sul de Minas Gerais, foi fundada a associação chamada União dos Supermercadistas Sulmineiros, Unissul. Os objetivos, segundo consta na ata de fundação da rede, são:

a) a integração empresarial para compartilhar ações conjuntas, visando possibilitar melhorias comerciais, políticas ou de serviços aos associados;

b) o desenvolvimento do espírito de associativismo e cooperativismo entre os associados;

c) parceriais na centralização de compras.

Dentre as obrigações determinadas desde o surgimento da rede podem-se destacar :

a) a obrigatoriedade de ser do ramo supermercadista;

b) boa imagem junto aos fornecedores da Unissul;

c) não ter filiais em cidades onde já existem membros da Unissul, salvo autorização;

d) ter faturamento médio dentro de mais ou menos $25 \%$ do faturamento médio dos membros da Unissul.

Atualmente, a Unissul reúne 13 associados em 16 cidades do Sul de Minas Gerais e 3 cidades no estado de São Paulo, em um total de 21 lojas, sendo 4 lojas próprias da Rede chamadas de Unissul S.A. - contando com mais de 1.850 funcionários e uma área de vendas de aproximadamente $23.000 \mathrm{~m}^{2}$ (UNISSUL, 2008). Desde que teve início, a rede Unissul vem 
Ari de Souza Soares, Cleber Carvalho de Castro, Mozar José de Brito \& Rosália Rodrigues

Alves

passando por significativas melhoras, chegando a ser apontada no ranking das redes 2006 (LUKIANOCENKO, 2006), como a rede mais eficiente do Brasil em faturamento por $\mathrm{m}^{2}$ (R\$ $16.666,00)$ e a mais eficiente em faturamento por check-out $(\mathrm{R} \$ 1.696 .453,00)$.

A Unissul conta, ainda, com um centro de distribuição (CD) próprio em Pouso Alegre (MG), sede da entidade, por meio do qual centraliza a distribuição das compras feitas em conjunto sobre horti-fruti, embalagens, produtos de marca própria, entre outros.

\subsection{Benefícios competitivos}

A competitividade proporcionada nas relações pessoais (Figura 1), indicou alta recorrência na rede de capital social $(42,9 \%)$, tratado como o cultivo de relações amigáveis entre os indivíduos, com o reconhecimento de que tais afetividades são conscientemente valorizadas pelos participantes, conforme pode ser observado no trecho 01.

(01) E criou-se uma amizade muito grande entre os associados e isso é que é importante. Aqui é uma família hoje, não é só negócio. Acho que quando você tem só o negócio, não é tão bom como quando você tem amizade junto (u2).

Ao mesmo tempo, destacou-se também, com igual recorrência, a categoria "aprendizado", referente às noções de trocas de informações, ideias e experiências obtidas por meio dos relacionamentos. Portanto, não fazem parte da categoria aprendizado, a transferência de conhecimentos formais por meio de treinamentos, consultorias, entre outros. 
Benefícios competitivos e conflitos em rede horizontal do setor supermercadista COMPETITIVIDADE_REL. PESSOAIS

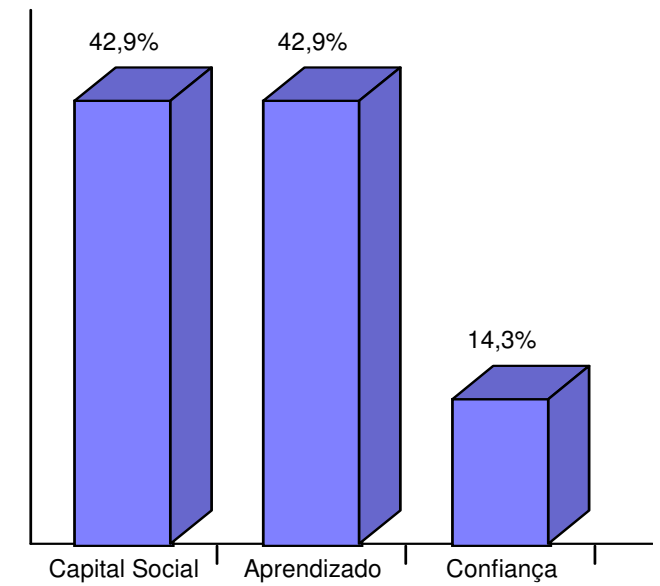

Figura 1: Benefícios competitivos obtidos pelas relações pessoais da rede Unissul Fonte: Dados da pesquisa exportados do software Sphinx léxica 5.0

A existência de capital social pode ser explicada porque um dos elos iniciais que possibilitou aglutinar a rede foi a preexistência de amizade entre os participantes. A iniciativa tomada por alguns teve como ponto de partida o convite feito aos amigos do mesmo ramo para a formação da rede. Outra justificativa é o grau de socialização do grupo em função do contato frequente (semanal) entre os participantes e por algumas amizades que foram se construindo ao longo do tempo para além dos assuntos discutidos na rede. Por exemplo, um dos entrevistados disse ser amigo de outro porque ambos possuem fazenda e compartilham assuntos aí relacionados.

Por outro lado, o aprendizado foi também uma categoria temática recorrente, dado que frequentemente era lembrado como elemento presente nas reuniões da rede, no sentido de troca de ideias e experiências (trecho 02). No entanto, este aprendizado, relacionado à diversidade de rotinas e à transferência de informações rápidas ou qualitativamente superiores (PODOLNY; PAGE, 1998), ocorre de forma intermitente e sujeita a se manifestar apenas após outros assuntos terem sido discutidos, já que, geralmente, ele surge de uma demanda individual dos participantes.

(02) A questão de troca de experiência, ela acaba saindo naturalmente. Você pega 15 pessoas que convivem semanalmente e que trabalham no mesmo ramo, naturalmente você acaba discutindo problemas: "ah, eu estou com um problema com funcionário, com fiscalização". Isso acaba surgindo e sempre tem alguém que já passou por aquilo ali. Sempre tem alguém que gosta de dar um palpite. Às vezes ninguém 
Ari de Souza Soares, Cleber Carvalho de Castro, Mozar José de Brito \& Rosália Rodrigues Alves

passou por aquele problema, mas só de você comentar com outras pessoas, eles têm outras visões sobre o mesmo problema. Tudo isso facilita bastante (u5).

Em virtude disso, embora no subconjunto dos benefícios competitivos obtidos a partir das relações pessoais o aprendizado seja um elemento importante, na competitividade como um todo ele é visto como um elemento periférico, tendo apenas um dos oito entrevistados o destacado como o principal elemento motivador para a sua entrada na rede.

O que se observa é um entendimento passivo, já que não foi explicitamente dito que estas trocas de ideias e experiências forneçam menos benefícios competitivos quando comparados aos outros elementos discutidos. Acrescente-se, ainda, que este aprendizado obtido pelas relações estabelecidas ocorre informalmente e de maneira casual e não estruturada.

A confiança, por sua vez, foi o item menos lembrado pelos entrevistados e está relacionada, neste trabalho, à ideia de redução de incertezas, no compartilhamento de risco para atividades que vão além do escopo da firma. O que foi possível perceber é que a palavra confiança é posta num continuum, de forma que fazer parte da rede "aumenta" a confiança, mas não que se "tem" confiança.

Nas atividades e processos internos da empresa (Figura 2), o principal elemento visto como benefício competitivo pelos entrevistados foi o jornal de ofertas $(42,9 \%)$. Isto pode ser explicado pelo fato de o jornal de ofertas funcionar como eixo coordenador de várias outras funções desempenhadas pela rede (trechos 03 e 04) e que não possuem o mesmo apelo visual e de resultados. O jornal, assim, congrega vários benefícios competitivos como promoções frequentes (duas vezes ao mês), preços baixos para o consumidor, alto giro de mercadorias, popularidade junto ao público, baixo custo de realização, entre outros.

(03) Uma das regras que a gente tem é que o jornalzinho tem que ser colocado em todas as lojas. A gente tem vínculos comerciais, vínculos de coisa que a própria firma exige (u4).

(04) Hoje a Unissul se mantém com a verba dos fornecedores de contrato e com as verbas de encarte. $\mathrm{O}$ fornecedor para colocar um produto no encarte ele paga um determinado valor. Tem essa parceria porque o encarte fica caro (u2). 
Benefícios competitivos e conflitos em rede horizontal do setor supermercadista

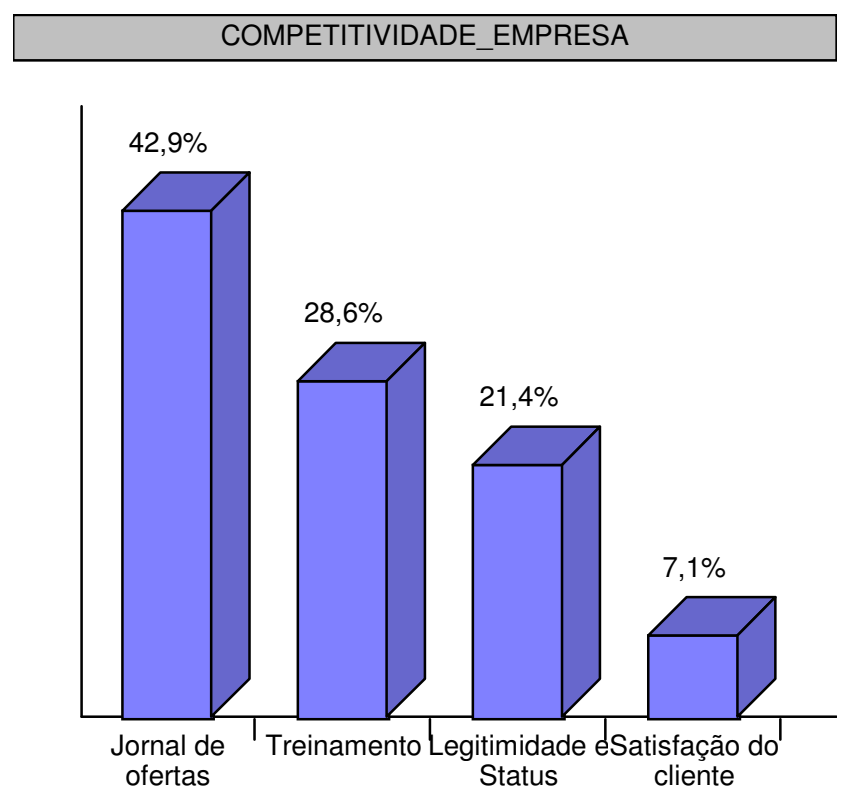

\section{Figura 2: Benefícios competitivos nas atividades e processos internos das empresas participantes da rede Unissul}

Fonte: Dados da pesquisa exportados do software Sphinx léxica 5.0

Outra categoria competitiva bastante lembrada foi o treinamento oferecido aos funcionários, apontado como benefício que tem ocorrido com frequência. Os entrevistados observaram que não apenas os custos de realização desses treinamentos são diluídos entre os participantes da rede, como também a difusão do conhecimento de uma loja para as demais é um fator bastante positivo (trecho 05). Este treinamento, como parte de um conjunto maior de iniciativas, também faz parte de uma visão orientada para o futuro, na busca pela profissionalização da rede, como ficou demonstrado na Figura 3, de expectativas da Unissul.

(05) A parte de treinamento também. Porque é uma troca de experiências. Porque, às vezes, você tem um profissional extremamente capacitado dentro de uma loja e essa capacidade profissional pode ser passada para os demais de outras lojas, compartilhada .(u8)

A legitimidade e o status foram apontados por alguns entrevistados como benefícios competitivos obtidos na qualidade de externalidades (ECONOMIDES, 1996) que a rede produz sobre os participantes. Por meio da valorização da imagem institucional do grupo e de relacionamento, de um lado, fazer parte da rede sugere maior liberdade de negociação e respaldo junto aos fornecedores e à indústria, bem como, de outro, traduz-se em respeito junto 
Ari de Souza Soares, Cleber Carvalho de Castro, Mozar José de Brito \& Rosália Rodrigues Alves

aos consumidores (trecho 06).

(06) hoje, a Unissul unida está com faturamento de 450 milhões de reais, seria a quarta empresa supermercadista de Minas Gerais. Se eu sou sozinho, eu não represento nada. Eu, junto, eu sou o segundo ou terceiro cliente Danone de Minas Gerais, eu sou terceiro cliente Bauducco de Minas Gerais, sou terceiro cliente Kraft de Minas Gerais, entendeu? É visto com outros olhos pela indústria. Isso eu consigo reverter em preços e benefícios para o meu cliente (u1).

A marca própria foi o principal benefício competitivo (50\%) originado da gestão operacional e organizacional da rede (Figura 3). Vários aspectos positivos foram apontados pelos entrevistados no uso de marca própria (trecho 07), como maior margem de lucros, fidelização de clientela, vantagem sobre a concorrência local e difusão da imagem da rede, entre outros.

(07) Devido à facilidade. Primeiro, pelo giro do produto, depois pela disponibilidade de indústrias pra produzir a marca própria. (...) A maioria dos produtos nossos de marca própria são líderes de mercado em nossas lojas. A gente tem uma qualidade compatível a do líder, e um preço mais acessível (u1).

\section{COMPETITIVIDADE_REDE}

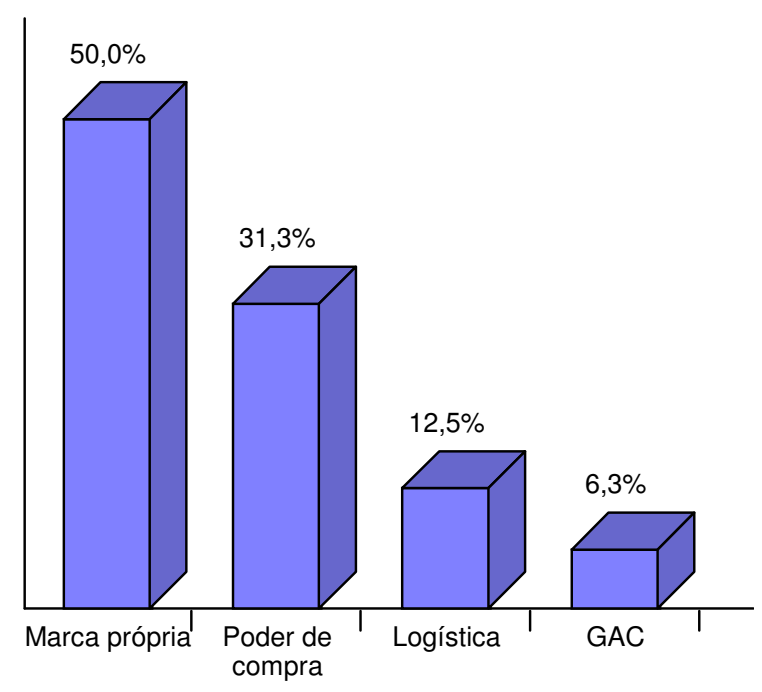

Figura 3: Competitividade na gestão operacional e organizacional da rede Unissul Fonte: Dados da pesquisa exportados do software Sphinx léxica 5.0

A marca própria contribui ainda para reforçar os elos de identidade do grupo, na 
Benefícios competitivos e conflitos em rede horizontal do setor supermercadista medida em que comercializam um produto comum a todos e que é próprio e único da rede. Trata-se, pois, da obtenção de vantagens pela criação de ativos específicos obtidos em conjunto. Além disso, a marca própria também foi apontada como um importante elemento harmonizador de conflitos que havia na rede.

$\mathrm{O}$ poder de compra surge como o segundo tema mais abordado como benefício competitivo. Embora seja um aspecto primário da relação de cooperação estabelecida, uma vez ser apontado como o principal elemento motivador de formação da rede, o poder de compra reflete ainda uma das atribuições básicas do setor, estando atreladas a ele várias outras atribuições. Deve-se incluir nesta lista, por exemplo, embalagem, reforma de lojas e ampliação de maquinário. A compra conjunta não se limita aos produtos a serem vendidos, mas abrange também aspectos organizacionais e operacionais de suporte às atividades gerais da rede.

A logística foi apontada como um benefício competitivo no que se refere à centralização, por meio de um centro de distribuição (CD) próprio, dos produtos comprados em conjunto. Segundo revelaram os entrevistados, os custos de manutenção do CD (coberto por meio de taxas pagas pelos participantes) são inferiores ao que se pagaria de frete para que os produtos comprados fossem distribuídos ponto a ponto. Segundo os entrevistados, o CD, com perspectivas de ampliação, é administrado com vistas à obtenção de lucro, no sentido de gerar superávits e ser auto-sustentável (trecho 08). O procedimento comum é as indústrias fazerem a entrega no $\mathrm{CD}$ e cada membro da rede buscar a sua parte, pagando uma taxa para isso.

(08) Outra forma de benefício é o próprio CD nosso. Que o nosso centro de distribuição não trabalha sem lucro. Ele presta um serviço para o associado, mas ele tem uma contrapartida de lucro. Então, ele não trabalha só servindo não (u4).

Interessante observar que o GAC foi pouco apontado no quadro de benefícios.

\subsection{Os conflitos percebidos pelos participantes da Rede Unissul}

O principal conflito pertencente à categoria temática das relações pessoais (Figura 4) foi apontado pelos entrevistados como incompatibilidades individuais $(58,3 \%)$, reforçando os resultados da $8^{a}$ Pesquisa Abras/SuperHiper de Redes e associações de negócios, que apontou 
Ari de Souza Soares, Cleber Carvalho de Castro, Mozar José de Brito \& Rosália Rodrigues Alves

que $67 \%$ dos problemas em rede devem-se às questões culturais entre os participantes (CARLESSI, 2008).

\section{CONFLITO_RELAÇÕES PESSOAIS}

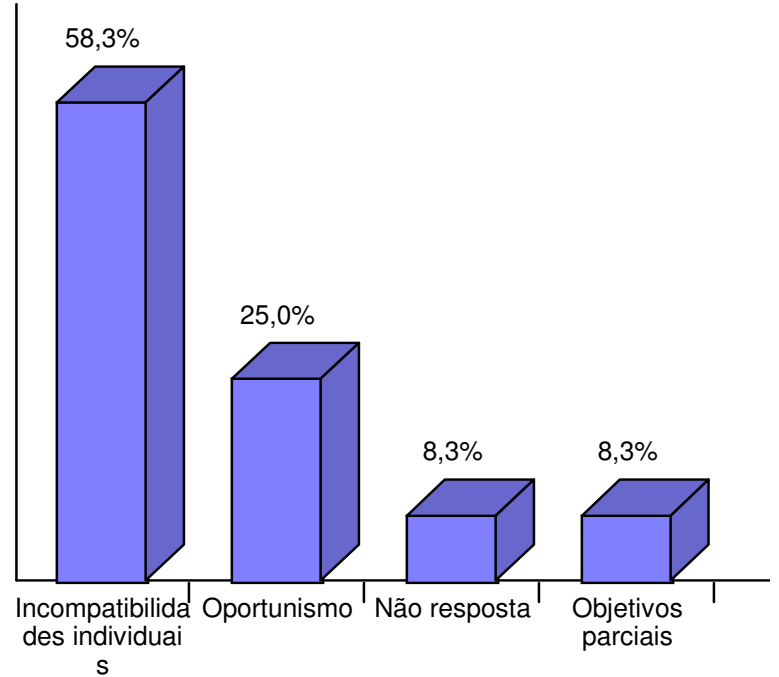

\section{Figura 4: Conflito nas relações pessoais da Rede Unissul}

Fonte: Dados da pesquisa exportados do software Sphinx léxica 5.0

As diferentes necessidades, interesses, valores e preferências entre os indivíduos frequentemente fazem surgir conflitos. É possível inferir que parte dessas incompatibilidades - conflitos percebidos pelas partes envolvidas (BOULDING, 1963) - decorre do fato de que os participantes possuem origens bastante variadas, tendo alguns deles explicitado que a região do sul de Minas é muito ampla, e a rede, estando distribuída ao longo deste espaço, incorpora essa herança de diversidades. Isso, por vezes, pode gerar conflitos de ordem pessoal (trechos 09 e 10), pela dificuldade de estabelecer um consenso nas decisões.

(09) Então, essa vaidade que existe no ser humano. Você está mexendo com 15 homens ali numa sala. Só que nós deixamos isso de lado. Nós colocamos a Unissul acima de tudo. Então, um procura respeitar o outro dentro das reuniões, a opinião de cada um, porque cada um tem uma visão. É abordado um assunto na reunião e é votado. Tudo lá é votado. Existe uma democracia lá dentro. Então, às vezes, o assunto está esquentando e o presidente vai lá e dá uma apaziguada nos ânimos (u2).

(10) Às vezes, as pessoas, no meio das discussões, esquecem de tudo o que a associação representa e o cara briga por causa de uma mixaria que não faz a menor diferença no negócio dele. Mas, é o orgulho, é a vontade de mostrar superior, de impor a opinião. E isso num grupo não dá certo (u6). 
Benefícios competitivos e conflitos em rede horizontal do setor supermercadista

O “oportunismo", segunda temática mais recorrente $(25,0 \%)$, é tratado como um tipo de conflito que se manifestou apenas esporadicamente e no início das atividades da rede, segundo pode ser observado nos trechos 11 e 12. Não havendo uma identidade grupal nos primórdios da rede e estando os valores coletivos ainda pouco inculcados, a prática oportunista ocorreu em casos isolados e seus praticantes acabaram não permanecendo na rede.

(11) É, existia muito disso no começo com o espertalhão. Por isso que nós começamos a colocar regras. Por exemplo, o cara não comprava da Unissul o encarte. Ele negociava a parte na loja dele e, às vezes, conseguia negociar coisa melhor. Então, por isso que nós estipulamos: são 7 "não" que você pode colocar no encarte, na redução dos produtos. De 80 produtos 7 você pode não comprar. E você tem o mínimo (u2).

(12) Com o tempo, a consciência de grupo foi crescendo dentro das pessoas. Então, chegou num ponto que todo mundo sabia que estava todo mundo ali para o grupo crescer. $\mathrm{O}$ grupo crescendo todo mundo ia junto. Isso foi um negócio muito legal (u6).

A categoria de "objetivos parciais", apontada por apenas um dos respondentes, está relacionada às diferenças de expectativas e objetivos futuros, no sentido de sobrepor o interesse individual sobre as metas coletivas. Esta orientação de futuro, diferente da orientação a ser tomada pela rede, é pequena (apenas 8,3\%), demonstrando que os objetivos parciais representam uma porção pequena dos conflitos que existem ou podem vir a existir na rede. Ao mesmo tempo, demonstra também uma coesão do grupo em sua orientação comum para os planos e projetos futuros da rede.

A categoria "não resposta" representa a situação em que o respondente declarou não perceber nenhum conflito na rede.

O conflito oriundo de aspectos operacionais e organizacionais da rede (Figura 5) ocorre, principalmente, devido a problemas com fornecedores (30\%). Estes problemas surgem em virtude da resistência apresentada pelos fornecedores em aceitar a filiação do supermercadista à rede (trecho 13). No intuito de enfraquecer o movimento associativista, práticas foram relatadas, como o boicote ou a oferta de maiores descontos para o supermercadista do que para a rede, visando minar a ideia de compra conjunta e, assim, as atribuições de ganhos conjuntos. 
Ari de Souza Soares, Cleber Carvalho de Castro, Mozar José de Brito \& Rosália Rodrigues Alves

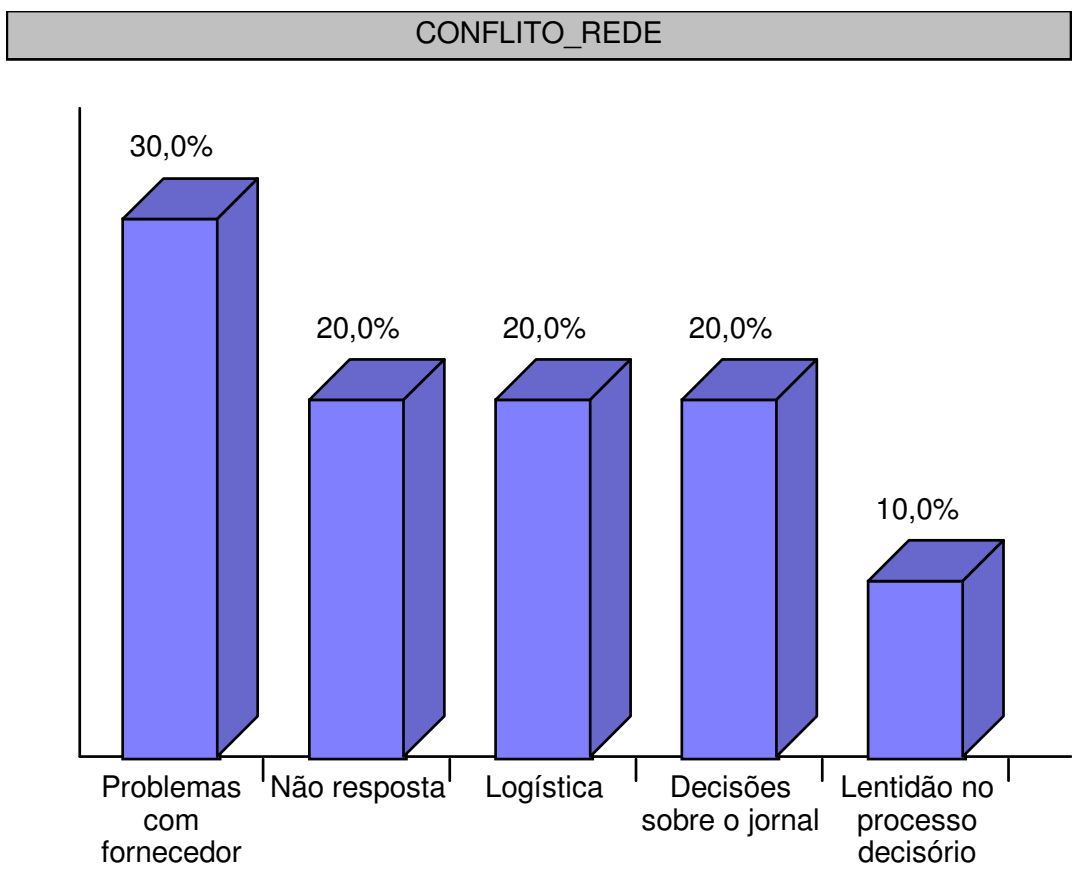

\section{Figura 5: Conflito de ordem operacional e organizacional da rede Unissul} Fonte: Dados da pesquisa exportados do software Sphinx léxica 5.0

Deve-se destacar, no entanto, que conflitos dessa ordem foram reduzidos com o passar do tempo, à medida que os fornecedores perceberam que podiam obter também vantagens com a existência das redes (trecho 14), já que, se por um lado, os fornecedores seriam pressionados pelo aumento do poder de compra dos supermercados, por outro lado, o volume de vendas aumentaria com esta parceria.

(13) De uma certa forma, dificulta um pouco o trabalho deles porque eles tinham uma liberdade muito grande de trabalho, individualmente, em cada loja. E hoje, isso não existe mais. Porque, às vezes, o que ele fizer na loja $\mathrm{A}$ não tem como ele esconder da loja B. Então, eles estão aprendendo a trabalhar dessa forma e estão se profissionalizando também nesse sentido (u8).

(14) Nos primeiros dois anos de formação da rede, tudo o que os fornecedores podiam fazer para que o negócio desse errado eles fizeram. Tudo que estava ao alcance deles. Eles iam na rede e ofereciam um preço mais caro, vinham na loja e falavam: "Olha, lá na rede eu não posso oferecer esse preço, pra você eu te faço". Aí vai da consciência do grupo. (...) Aí, com o tempo, os fornecedores entenderam que este não era o caminho e começaram a trabalhar mais a rede. E aí eles viram que lá era uma grande oportunidade de fazer volume (u6). 
Benefícios competitivos e conflitos em rede horizontal do setor supermercadista

A logística também foi uma questão bastante abordada e que, embora contornada em parte pelo CD da rede, é criticada pelos participantes, dada a extensão da região sul de Minas Gerais, conforme relatado no trecho 15 . Os conflitos podem surgir nesse nível devido ao fato de alguns participantes estarem localizados mais distantes do que outros, em relação a Pouso Alegre, local de operação do CD. A preocupação apontada era o atraso no recebimento de mercadorias e, com isso, perda de receita pela inviabilidade de distribuir o jornal de ofertas, na situação dos produtos ainda não estarem disponíveis nas prateleiras.

(15) Eu mesmo, aqui, já tenho uma certa dificuldade. Problemas com a logística porque eu estou bem próximo à divisa do estado. Então, vamos dizer, eu aqui sou o último a receber. Porque eu estou no fim da linha. Muitas vezes, a mercadoria demora pra chegar aqui pra mim. Muitas vezes acontece, por exemplo, a gente tem a programação de um encarte feito, os encartes a gente já distribuiu e a mercadoria não chegou pra mim (u7).

As decisões sobre o jornal foram apontadas com a ressalva de que este problema já está relativamente controlado. Os problemas e, por conseguinte, os conflitos percebidos sobre o jornal surgiam pelas diferentes opiniões acerca da colocação de produtos regionais que, tendo muito giro em algumas cidades, não eram bem aceitos em outras. A solução encontrada foi passar a substituir os produtos regionais pelos produtos de marca própria do grupo, estabelecendo um denominador comum e, ao mesmo tempo, eliminando o favorecimento para este ou aquele produto de determinada localidade.

Vale lembrar também que o grupo reduziu os conflitos relativos ao jornal a partir do momento em que, da lista de oitenta produtos a serem comprados em conjunto, cada participante pôde dizer "não" a sete produtos. Com esta prática, tanto algumas perdas foram reduzidas quanto o nível de satisfação com a escolha dos produtos foi melhorado.

\section{Considerações finais}

No presente estudo, os benefícios competitivos proporcionados às empresas do setor supermercadista participantes de uma rede horizontal foram agrupados em três grupos, a saber: 1) relações pessoais, 2) atividades e processos internos da empresa e 3) gestão operacional e organizacional da rede. Por sua vez, os conflitos de interesses percebidos por estas empresas participantes de rede compreenderam: 1) relações pessoais e 2) gestão 
Ari de Souza Soares, Cleber Carvalho de Castro, Mozar José de Brito \& Rosália Rodrigues Alves

operacional e organizacional da rede.

Os resultados evidenciam que os principais benefícios competitivos podem ser apontados como o capital social e o aprendizado nas relações pessoais entre os membros, o trabalho conjunto na confecção do jornal de ofertas, programas de treinamento e produtos de marca própria. Esses benefícios ajudam a reduzir os custos operacionais, aumentar as vendas e recursos disponíveis para atividades que requeiram maiores investimentos, além de fortalecer os participantes de possíveis ações dos concorrentes locais.

Conforme relato dos participantes da rede, os ganhos de competitividade pela ação conjunta são reais e significativos. Todavia, participar de uma rede significa também estar disposto a abandonar certas práticas obsoletas e arcar com o ônus intertemporal de ganhos e perdas. O que isso significa? Basicamente, investir e apoiar ideias que trarão retorno num intervalo de tempo superior ao que os participantes individuais costumavam trabalhar. É, neste sentido, ter planejamento e estratégias de longo prazo, percebendo o ambiente competitivo como mais amplo e repleto de desafios que passam a envolver, também, os grandes grupos de varejo que atuam em todo país.

Por outro lado, os conflitos emergem em virtude de incompatibilidades individuais, de problemas com fornecedores e de decisões sobre o jornal de ofertas. Tais conflitos são vistos como barreiras ao pleno aproveitamento destes benefícios, na medida em que minam a cultura do associativismo pela satisfação de objetivos parciais que, por vezes, evoluem para práticas oportunistas.

Foi possível perceber que os participantes da rede atuam de forma conjunta como mediadores na resolução dos conflitos. Isto ocorre pela natureza horizontal do arranjo, onde a solução destes conflitos não ficam relegadas apenas a um gestor. Além disso, o número reduzido de participantes facilita este processo, dado que a proximidade dos relacionamentos torna possível a existência de um ambiente onde todos se sentem "parte do problema", assumindo uma posição ativa na busca por soluções. Este comportamento repercute de forma indireta como benefício competitivo, na medida em que torna as ações mais congruentes, isto é, com menos objetivos parciais e menor incidência de práticas oportunistas, como foi possível constatar.

Ao mesmo tempo em que algumas questões desta pesquisa foram sendo respondidas, outras indagações surgiram a partir do panorama de fatos observados, reclamando por novas 
Benefícios competitivos e conflitos em rede horizontal do setor supermercadista pesquisas que avancem sobre este trabalho. Assim, Colocam-se em pauta novos temas que, acredita-se, nos ajudará a compreender melhor o fenômeno das redes, como:

a) o conflito como fatores positivos ou negativos na obtenção de benefícios competitivos;

b) a relação entre quantidade de membros de uma rede horizontal e a natureza dos conflitos existentes;

c) os efeitos que as redes exercem (externalidades) sobre as empresas locais não filiadas em rede.

Em relação ao setor supermercadista, foi possível observar a tendência das redes de se firmarem como um importante formato organizacional deste setor, não apenas pelos dados estatísticos apresentados, mas também pela própria percepção dos participantes entrevistados. Após as entrevistas realizadas, a observação de campo e a leitura de artigos e reportagens discutindo o crescente e forte movimento de adesão às redes, fica a seguinte pergunta: Poderão no futuro as PME's supermercadistas sobreviverem fora de uma rede? A pergunta é instigante, pois reflete também outra questão: Quais são os limites de uma rede?Até que ponto as redes podem não ser uma boa opção?

Estas questões, ainda não respondidas, fazem das redes um objeto de estudo rico em possibilidades. Entendê-las e explicá-las com base em teorias e métodos é um caminho árduo, porém, gratificante, na medida em que nos mostra as diversas facetas deste fenômeno, tanto em seus aspectos positivos quanto negativos.

\section{REFERÊNCIAS}

ALTER, C. An exploratory study of conflict and coordination in interorganizational service delivery systems. Academy of Management Journal, 33(3), 478-502. 1990.

ASSAEL, H. Constructive role of interorganizational conflict. Administrative Science Quartely, 14, 573-582, dec. 1969.

BALESTRIN, A.; VARGAS, L. M. A dimensão estratégica das redes horizontais de PMEs: teorizações e evidências. Revista de Administração Contemporânea. Edição Especial, p. 203, 2004.

BARDIN, L. Análise de conteúdo. 4aed. Lisboa, Portugal: Edições 70, 2007.

BAUM, J. A. C.; INGRAM, P. Interorganizational learning and network organization: toward a behavioral theory of the interfirm. In: MARCH, J. G., AUGIER, M. (Eds.). A tribute to Richard M. Cyert. Aldershot UK: Edward Elgar. 2000.

BENGTSSON, M.; KOCK, S. Cooperation and competition in relationships between 
Ari de Souza Soares, Cleber Carvalho de Castro, Mozar José de Brito \& Rosália Rodrigues Alves

competitors in business network. Journal of Business \& Industrial Marketing. v.14, n.3, pp.178-193, 1999.

BOULDING, K. E. Conflict and defence: a general theory. New York: Harper \& Row, 1963.

BRANDENBURGER, A. M.; NALEBUFF, B. J. Co-opetition. New York: Doubleday, 1996.

BROWN, L. D. Managing conflict at organizational interfaces. MA: Addison-Wesley, 1983.

CARLESSI, R. Pesquisa de redes: setor busca crescimento sustentável. SuperHiper, ano 34, n. 390, p.58-79, set. 2008.

CARVAlHO, A. Centrais de negócios: desafios da união. Supermercado Moderno. São Paulo, v. 36, n. 7, p. 36-42, jul. 2005.

CARVALHO, M. S.; GHISI, F. A.; MARTINELLI, D. P. Uma pesquisa qualitativa sobre as redes de compra no Brasil como alternativa de sobrevivência dos pequenos e médios supermercados. In: ANGELO, C. F.; SILVEIRA, J. A. G. (Org.). Varejo competitivo. 1 ed. São Paulo: Saint Paul Institute of Finance, v. 8, p. 327-353. 2004.

CASAROTTO FILHO, N.; PIRES, L. H. Redes de pequenas e médias empresas e desenvolvimento local: estratégias para a conquista da competitividade global com base na experiência italiana. São Paulo: Altas, 1998.

CASTELLS, M. A Sociedade em rede: a era da informação - economia, sociedade e cultura. 7. ed. São Paulo: Paz e Terra, 2007.

COOK, K. S. et al. The distribution of power in exchange networks: theory and experimental results. The American Journal of Sociology, v.89, n.2, p.275-305, 1983.

DENZIN, N. K., LINCOLN, Y. S. Introduction: the discipline and practice of qualitative research, in DENZIN, N. K., LINCOLN, Y. S. (Eds),Handbook of qualitative research, Sage, London, p.1-28. 1994.

DYER, J. H.; SINGH, H. The relational view: cooperative strategy and sources of interorganizational competitive advantage. Academy of Management Review, New York, v. 23, n.4, p. 660-679, Oct. 1998.

ECONOMIDES, N. The economics of networks. International Journal of Industrial Organization, 14, n. 2, mar.1996.

ELG, U.; JOHANSSON, U. Decision making in inter-firm networks as a political process. Organization Studies, Vol. 18, No. 3, p.361-384, 1997.

ERNST, D. Inter-firms network and market structure: driving forces, barriers and patterns of control. Berkeley, CA: University of California, 1994. 
Benefícios competitivos e conflitos em rede horizontal do setor supermercadista

EASTON, G.; ARAUJO, L. Non-economic exchange in industrial network. In: AXELSSON, B.; EASTON, G. (Ed.). Industrial networks: a new view of reality.London: Routledge, 1992.

FREITAS et al. Pesquisa interativa e novas tecnologias para coleta e análise de dados usando o sphinx®. Canoas: Sphinx, 2002.

GASKI, J. F. 1984. The theory of power and conflict in channels of distribution, Journal of Marketing, 48: 9-29. 1984.

GRANDORI, A.; SODA, G. Inter-firm networks: antecedents, mechanisms and forms. Organization Studies. v.16, n.2, p.1-19, 1995.

GRANOVETTER, M. Economic action and social structure: the problem of embeddedness. American Journal of Sociology. v. 91, n.3, p. 481-510. 1985.

GRISCI, C. L. I. ; DENGO, N. Universidades corporativas: modismo ou inovação? Revista Eletrônica de Administração, Porto Alegre, v. 9, p. 01-16, 2003.

GULATI, R.; NOHRIA, N.; ZAHEER, A. Strategic networks. Strategic Management Journal, v. 21, p. 203-215, 2000.

JEHN, K. A. A multimethod examination of the benefits and detriments of intragroup conflict. Administrative Science Quartely, 40(2), p.256-282, 1995.

KOEN, C. I.; BEUGELSDIJK, S.; NOORDERHAVEN, N. G. Organizational culture and network embeddedness. In: RAHIN, M. A. (Ed.). Current topics in management. New Jersey: Transaction Publishers, 2006.

KRUG, B. Networks in cultural, economic and evolutionary perspective. ERIM Report Series Reference No. ERS-2003-050-ORG. January, 2003.

LAINE, A. Sources of conflict in cooperation between competitors. Proceedings of the 18th Annual IMP Conference, Dijon, France, September 5-7, 2002.

LUKIANOCENKO, M. Ranking das redes 2006: profissionalização dá resultado. SuperHiper, São Paulo, ano 32, n. 368, p.76-88, set. 2006.

MACHADO, D. P. N.; ANTUNES, A. G. Estudos de liderança: um estudo nas agências de um banco de varejo público em Santa Catarina. Revista de Negócios, v. 12, p. 3-19, 2007.

MARSDEN, P. V. Restricted access in networks and models of power. American Journal of Sociology, 88: 686-717, 1983.

NAKANO, D. N. Fluxos de conhecimento em redes interorganizacionais: conceitos e fatores de influência. In: AMATO NETO, J. (Org.) Redes entre organizações: domínio do conhecimento e da eficácia operacional. São Paulo: Atlas, 2005.

NASCIMENTO, L. F.; PESSOA, R. W. A. Qualidade de vida no trabalho: uma questão de responsabilidade social. Revista Eletrônica de Administração, v. 13, p. 518, 2007. 
Ari de Souza Soares, Cleber Carvalho de Castro, Mozar José de Brito \& Rosália Rodrigues Alves

NOHRIA, N. Is a network perspective a useful way of studying organizations? In: NOHRIA, N.; ECCLES, R. G. (Eds.). Networks and organizations: structure, form, and action. Boston, Massachusetts: Harvard Business School Press, 1992.

OLIVARES, J. E. L. Análise da estrutura organizacional em rede e suas negociações no contexto de alianças estratégicas, 2003. Tese (Doutorado em Administração) - Faculdade de Economia e Administração, Universidade de São Paulo, 2003.

OUCHI, W. G. Markets, bureaucracies and clans, Administrative Science Quarterly, 25, March, p. 129-141, 1980.

PASCALE, R. T. Managing on the edge: how successful companies use conflicts to stay ahead. London: Penguin Group, 1990.

PERROW, C. Small-firm networks. In: NOHRIA, N.; ECCLES, R. G. Networks and organizations: structure, form, and action. Boston: Harvard Business School Press, 1992.

PODOLNY, J. M.; PAGE, K. L. Network forms of organization. Annual Review of Sociology 24: 57-76, 1998.

PONDY, L. Organizational conflict: concepts and models. Administrative Science Quarterly, 12, 296-320. 1967.

POZZEBON, M.; FREITAS, H.; PETRINI, M. Pela integração da inteligência competitiva nos interprise information systems. Revista Ciência da Informação, v. 26, n. 3, jun 1997.

RAHIM, M. A. Empirical studies on managing conflict. The International Journal of Conflict Management, 11(1), 5-8. 2000.

RHENMAN, F.; STROMBERG, L.; WESTERLUND, G. Conflict and cooperation in business organizations. New York \& Chichester: John Wiley, 1970.

SCHER, M. Japanese interfirm networks: "High-trust" or relational access? In: GRANDORI, A. Interfirm networks: organization and industrial competitiveness. London: Routledge, 1999.

STROEHER, A. M.; FREITAS, H. O uso das informações contábeis na tomada de decisão em pequenas empresas. Revista RAUSP, v. 1, n.1, Jan-Jun 2008.

TRIVIÑOS, A. R. S. Introdução a pesquisa em ciências sociais: pesquisa qualitativa em educação. São Paulo: Atlas, 1987.

UNISSUL - União dos supermercadistas mineiros. Informativo. 2008.

VIEIRA, V. A. Características e variações da pesquisa em marketing. Revista Científica da 
Benefícios competitivos e conflitos em rede horizontal do setor supermercadista

Fae, Curitiba, PR, v. 5, n. 1, p. 61-70, 2002.

YIN, R. K. Estudo de caso: planejamento e métodos. 2. ed. Porto Alegre, Bookman, 2001.

ZENTES, J.; BERNHARD, S. Allied groups on the road to complex networks. Tecnology in Society 22, p.133-150, 2000.

\title{
RESUMO
}

A estratégia de formação de redes no setor supermercadista brasileiro tem se tornado uma importante alternativa para as pequenas e médias empresas (PMEs) que buscam melhores condições competitivas para enfrentar a concorrência das grandes empresas do setor. Nesse sentido, este estudo foi realizado com o objetivo de analisar os benefícios competitivos e os conflitos de interesses percebidos na participação de empresas do setor supermercadista em uma rede horizontal na região sul de Minas Gerais. Para isso, realizou-se um estudo multicasos qualitativo, com uso de dados secundários (principalmente de associações de classe) e dados primários coletados por meio de entrevistas realizadas com oito participantes da rede. As entrevistas foram tratadas por meio de análise de conteúdo, com auxílio do software Sphinx léxica 5.0. Os resultados evidenciam que os principais benefícios competitivos podem ser apontados como o capital social e o aprendizado nas relações pessoais entre os membros, o trabalho conjunto na confecção do jornal de ofertas, programas de treinamento e produtos de marca própria. Por outro lado, os conflitos emergem em virtude de incompatibilidades individuais, de problemas com fornecedores e de decisões sobre o jornal de ofertas. Tais conflitos são vistos como barreiras ao pleno aproveitamento destes benefícios, na medida em que minam a cultura do associativismo pela satisfação de objetivos parciais que, por vezes, evoluem para práticas oportunistas.

Palavras-chave: Redes horizontais; Benefícios competitivos; conflitos; setor supermercadista; sphinx 5.0.

\section{COMPETITIVE BENEFITS AND CONFLICTS IN HORIZONTAL NETWORK OF THE SUPERMARKET SECTOR}

\begin{abstract}
The strategy of forming networks in the Brazilian supermarket sector has become an important alternative for Small and Medium Enterprises (SMEs) which are searching for better positions to face competition from large companies in the industry. In this sense, the purpose of the study is to analyze the competitive benefits and perceived conflicts of interest in the participation of the supermarket sector in horizontal networks in the southern region of Minas Gerais. Thus, a multicase, qualitative study was conducted, using secondary data (mainly by industry associations) and primary data collected through interviews with 8 participants of the horizontal network (Unissul). These network were chosen because of its strong presence in the southern region of Minas Gerais. The interviews were handled by Content Analysis, with the help of the software Sphinx lexica 5.0. The results proves that main competitive benefits can be appointed as a social capital and relationship learning among members, the joint work in promotional newspapers production, training programs and own brands. On the other hand, the conflicts arised owing to individuals incompatibilities, supplier's problem and decisions about promotional newspapers. This conflicts are seen as barriers to the complete use of these benefits, to the extent that the associativism undermine
\end{abstract}


Ari de Souza Soares, Cleber Carvalho de Castro, Mozar José de Brito \& Rosália Rodrigues Alves

the culture of the satisfaction of partial goals, which sometimes evolve to opportunistic practices.

Keywords: horizontal networks; Competitive benefits; Conflicts, Supermarket sector; Sphinx 5.0 . 